\title{
Comparing one- and two-piece dental abutments under dynamic loading: A 3-D finite element analysis
}

\author{
Saba Mohammadpour \\ Msc in biomedical engineering with specialization in biomechanics ,School of Biomedical Engineering, \\ Islamic Azad University-Science and Research Branch, Tehran, Iran (corresponding author) \\ Siamak Khorramymehr \\ phd in biomechanics, School of Biomedical Engineering, \\ Islamic Azad University-Science and Research Branch, Tehran, Iran
}

\begin{abstract}
Background.Using titanium alloys as an implant material has acheived a huge interest recently due to its high biocompatibility as well as stable fixation between implant and human bone. A finite element model is needed to design standard implants. The purpose of this study was to compare two types of dental abutments which are commonly used in screw-retained restorations under dynamic loading which can simulate masification forces and evaluate the influence of the implant-abutment connection design to prevent screw-loosening, abutment fracture and implant failure.
\end{abstract}

Methods.First a a high-quality scanner was used to model an implant with One- and two-piece dental implant abutments which were placed on each in Abaqus software version 6.14. All the components of the system were presumed linear elastic, homogenous and isotrpic.After loading (250 $\mathrm{N}$ vertical force with 4 Hz frequency), von Mises stress was recorded.

Results. The maximum stress in one-piece abutment body was less than two-piece one (91 Mpa vs. 142 Mpa).In addition the maximum stress value in the last thread of the screw of two-piece abutment was significantly higher than the body of two-piece abutment (424 Mpa vs.142 Mpa).

Conclusion.Occurance of stress concentration in the last threads of two-piece abutment leads to screwloosening, fracture of the screw from the threads and finally prostheses' fracture. Although integrated screwed-in abutments are highly resistant to screw-loosening two-piece abutments are better clinical choices considering less stress concentration developed in bone. The phenomenon of screw-loosening helps the clinician to recognize over-loading and lets them prevent catastrophic mechanical failure of the implant and fracture of the peri-implant bone.

Key Words: Biomechanics, Dental Implants, Screw Loosening, Stress, Implant-Abutment Connection

\section{Introduction}

Titanium is a widespread accepted material used in implant dentistry due to its mechanical properties and biocompatibility which made it an excellent substitute for the root of the lost tooth. However, long-term followup studies on implant treatment plans indicate that many complications occur after the prosthetic phase. These complications include soft tissue inflammation, bone loss, abutment screw loosening, abutment screw fracture, and loss of osseointegration. As is evident in recent literature Goodacre CJ (2003) declared successful osseointegration occurs in more than $95 \%$ of the cases following the surgical phase, regardless of the implant system used. Therefore, it is not surprising that Esposito M (1998) have demonstrated that late failures (after more than 1 year of loading) are due to overload in $90 \%$ of cases, with $10 \%$ being attributed to peri-implantitis. A thorough understanding of implant biomechanics makes it possible to optimize treatment planning and reduce any risk of functional complications and failures. The application of engineering knowledge in dentistry has contributed to an understanding of biomechanical aspects related to implantology.Finite element analysis (FEA) was initially developed in the early 1960 s to solve structural problems in the aerospace industry but has since been extended to implant dentistry.

Implant-supported prostheses are categorized into two major types; screw-retained and cement-retained restorations.As Vigolo P and Chee W $(2004,1999)$ suggested each type of restoration has some advantages and their selection is mostly based on the clinician's preference. According to Heckmann et al (2004) there is no difference between the precision of fit of these two types of restorations. Moreover, the stress developed in the peri-implant bone supporting screw-retained and cement-retained restorations was reported to be similar. 
Walton JN (1994) demonstratd that screw-retained restorations have several advantages over cement-retained ones, including retrievability, higher stability and security of implant-abutment connection. As Ramos MB (2014) suggested they can be fabricated with two types of abutments: one-piece and two-piece abutments. Theoretically, given a decrease in the number of screws and the micro-motion of the components in the nonsegmented abutments, the amount of stresses transferred to the bone would in-crease.There are a numbers of publications on the effects of implant diameters, platform switching design, ridge diameters and inclination of load applied to an implant on stress/strain patterns in the surrounding bone. However, information regarding stress patterns within an implant and the effects of various types of connections on load transfer are rare. A load is applied to the superstructure part of an implant, and transferred to the abutment. The abutment carries the load to the fixture and bone through the implant-abutment and implant-bone connection. This load is finally applied to the surrounding bone. Therefore, the implant-abutment connection area has an important role in modifying this load. A precise and well-designed connection leads to high rotational stability. Finally, a stable interlocking fit between implant and abutment reduces the occurrence of micro-movements and guarantees that the retaining screw will remain in place without being exposed to the risk of screw loosening or screw breakage. There are different kinds of internal connections on the market and some of them are used more frequently than the other ones regardless of their clinical outcomes. Therefore, this study was designed to examine the role of two different types of connection design on stress/strain distributions within an implant system.

\section{Methods}

\subsection{Materials}

Two different types of abutments which were commonly used in dental implant treatment plans were selected and 3D models of a dental implant system (BioHorizons, internal tapered bone level, BioHorizons Co. Birmingham, USA), $12 \mathrm{~mm}$ in length and $4.6 \mathrm{~mm}$ in width at the body and $4.5 \mathrm{~mm}$ at the platform, were simulated in Abaqus 6.14 .

Sample A : Implant with Two-piece abutment , 1.5-mm deep internal hex , 8-mm abutment height from hex , 5$\mathrm{mm}$ abutment screw height

Sample B :Implant with One-piece abutment , 1.5-mm deep internal hex , 8-mm abutment height from hex

\subsection{Model Geometry}

The present study was based on a real implant system available on the market (BioHorizons Co. Birmingham, USA).To decrease the confounding factors, implants which are used for comparing two types of mentioned abutments possess similar dimensions.Moreover the computerized models of the bone and the fixture were assumed with the same dimentions for both types of the abutments. As a result both implants were modeled with length of $12 \mathrm{~mm}$ and diameter of $4.6 \mathrm{~mm}$. In order to model the abutments exactly the same as the actual form, the real ones were scanned with a high-quality scanner (Scanmaker i800, Mi-crotech, Shanghai, China). Thuse, it was possible to access all the data regarding shapes and dimensions of the inner and outer surfaces of the abutments as real as possible. All the above data were used to produce computerized models by Abaqus software as shown in Figure 1.

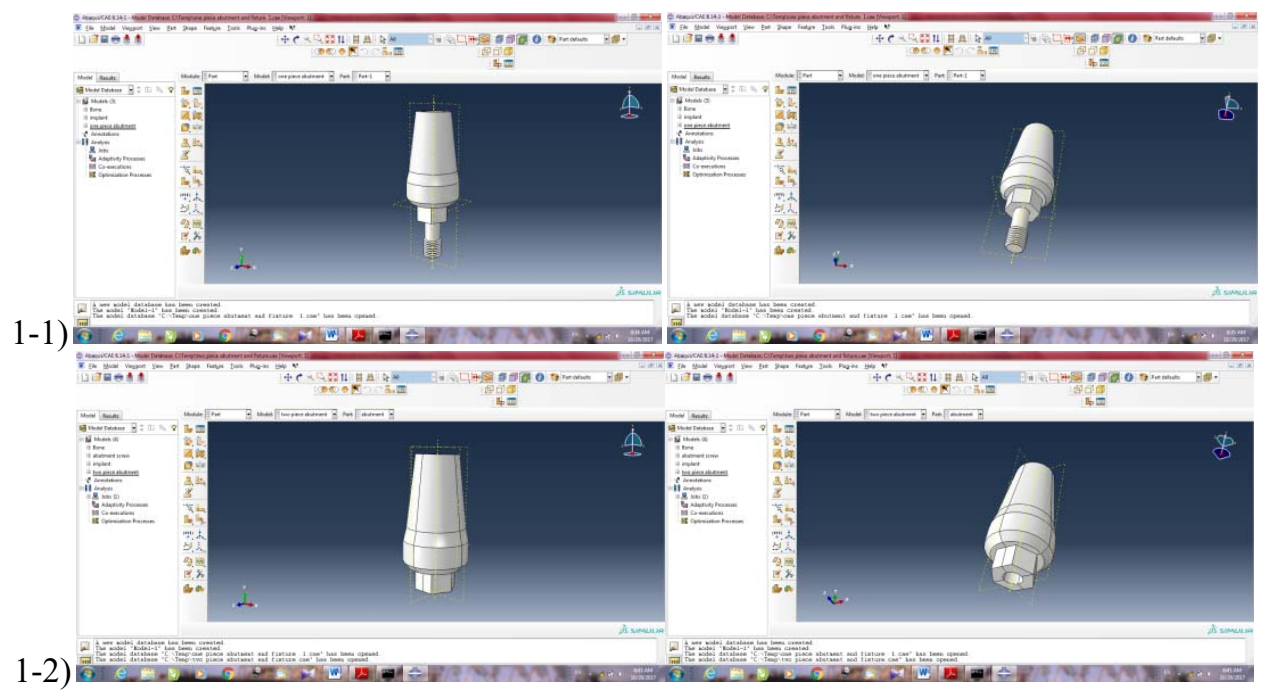




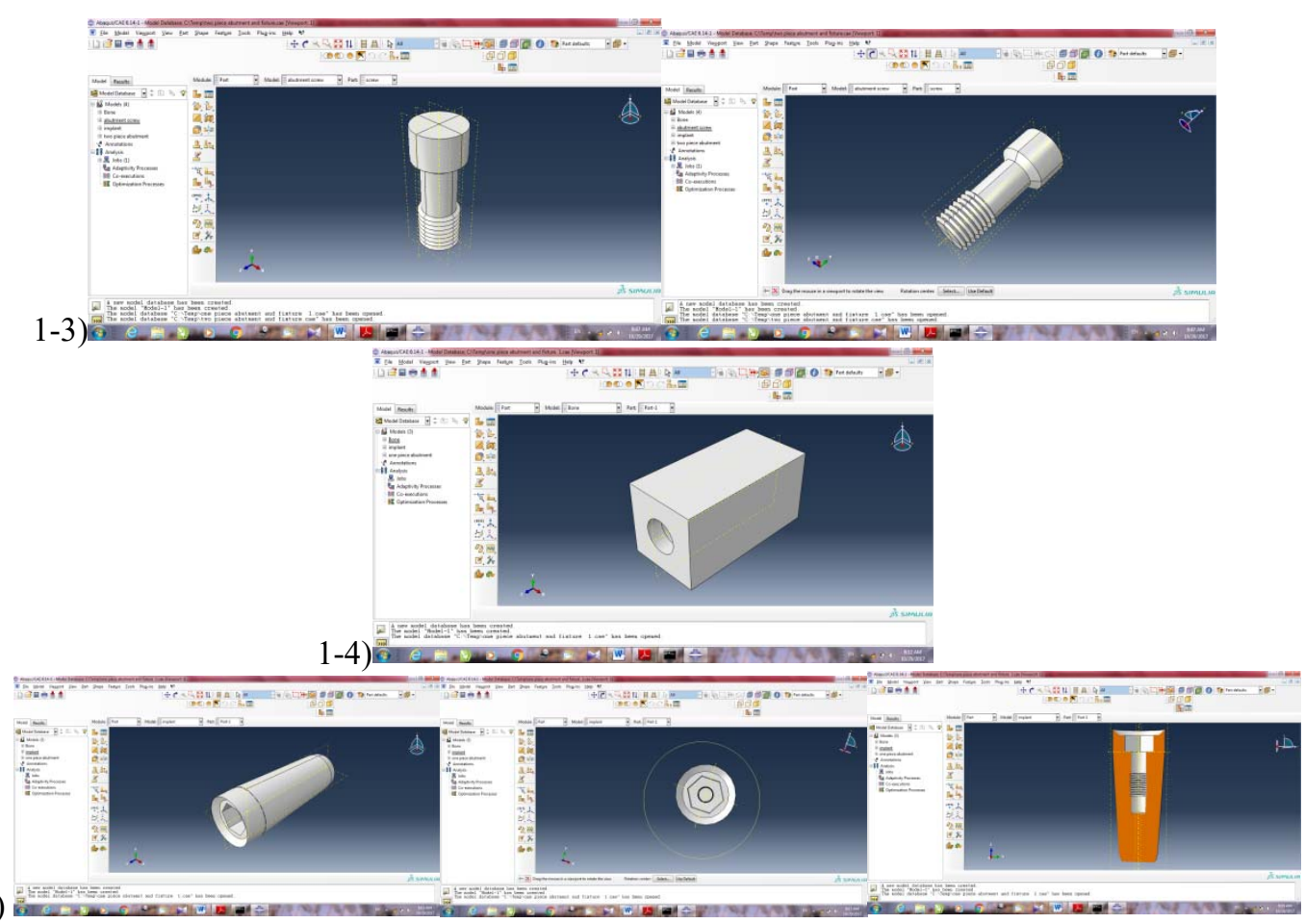

Figure1. Geometry of models of the components of the system of sample A and B 1-1)One-piece abutment.1-2)Two-piece abutment.13)Two-piece abutment screw. 1-4) Bone.1-5) Implant

\subsection{Material Properties}

All the materials used in the models consisted of implants, abutments, and abutment screwsand the bone were presumed to be as homogeneous, isotropic and linearly elastic as one another. The material properties, including modulus of elasticity and Poisson's ratio used in FE model, are listed in Table 1.

Table 1. Physical properties of different materials used in the present study

\begin{tabular}{ccc}
\hline Components & Modulus of elasticity & Poisson's ratio \\
\hline Implant & 102000 Mpa & 0.35 \\
Abutment - abutment screw & 114000 Mpa & 0.38 \\
Bone & 13400 & 0.3 \\
\hline
\end{tabular}

The bone-implant interface was assumed to be perfect, simulating complete osseointegration. Therefore, the connections between implant-bone were designed to be bonded. Within the implant system, FEM modeling was performed by implementing bonded conditions on the abutment-implant interfaces.

To reduce the computing time and increase validity of our data all the models were constructed using threedimensional 4-node tetrahedral elements as they are shown in Figure 2. All the nodes at the base of 3D models were restrained to determine the boundary conditions. Although this type of modeling with hexahedral elements is the most compatible for linearly elastic materials, hexahedral modeling could not be used due to complex geometry. The number of elements and nodes used in this study are listed in Table 2.

Table 2. Number of elements and nodes in the samples

\begin{tabular}{cll}
\hline Components & Nodes & Elements \\
\hline One-piece abutment & 4489 & 20496 \\
Abutments screw in two-piece abutment & 1265 & 5643 \\
Body of two-piece abutment & 3909 & 17518 \\
Implant & 5231 & 24259 \\
Bone & 4593 & 23108 \\
\hline
\end{tabular}




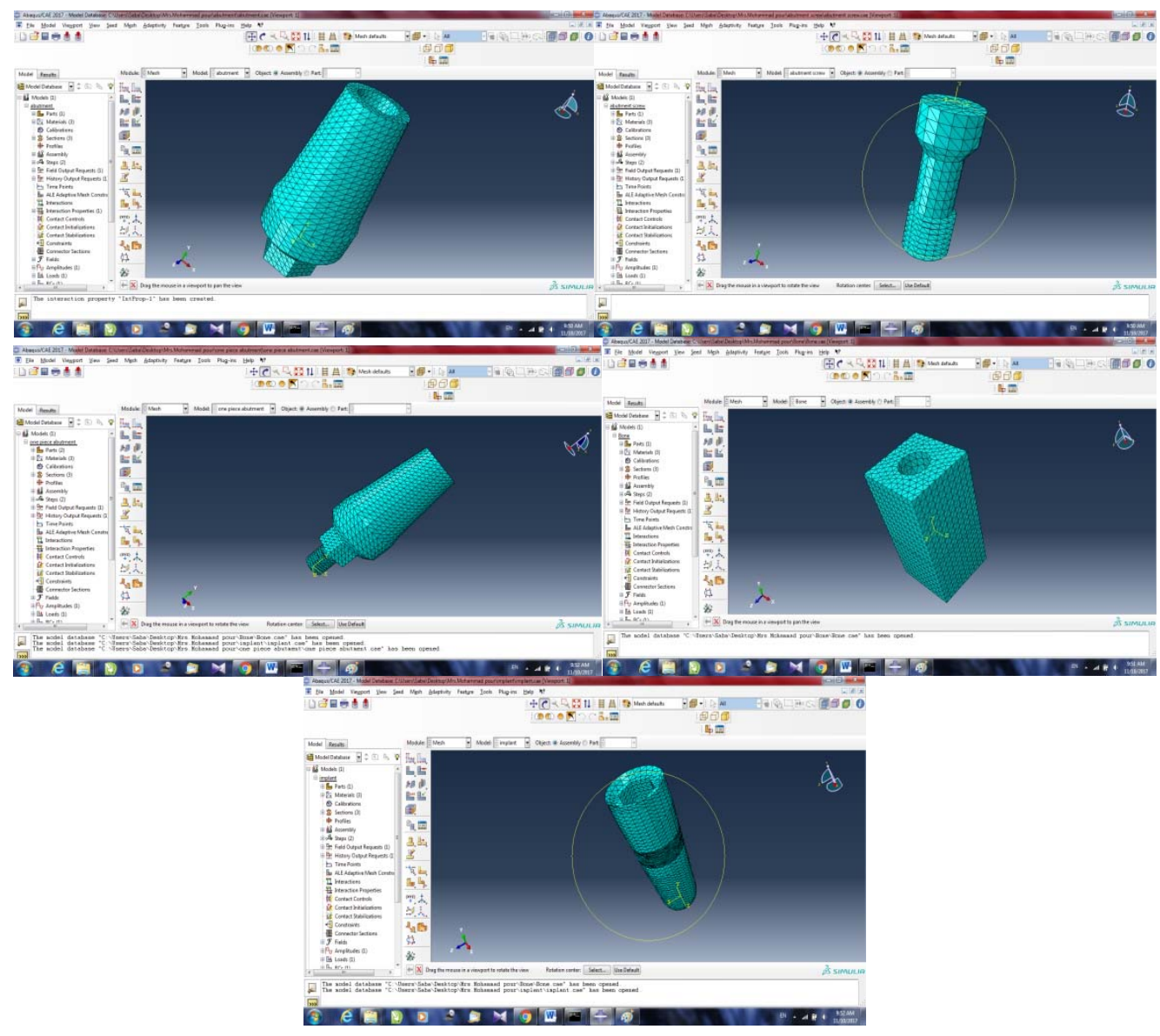

Figure2. Meshed models of the components of the system of sample A and B

\subsection{Loading Conditions}

For simulating masification functional forces a $250-\mathrm{N}$ vertical force with $4 \mathrm{~Hz}$ frequency was applied to the entire outer surface of the abutments in both systems.

\subsection{Stress/strain Analysis}

The computerized models were transferred to Abaqus software and all the conditions mentioned previously (material properties, interface condition, meshing and loading) were included in this software.

\subsection{Boundary Condition of Modeling}

One of the most important criteria in FEA is the characteristic features of connection between various components.This study simulated an osseointegrated implant with a screwed rough surface; therefore, a 'fixed bond' condition was set as an approximation at its inter face with bone.

3-1)
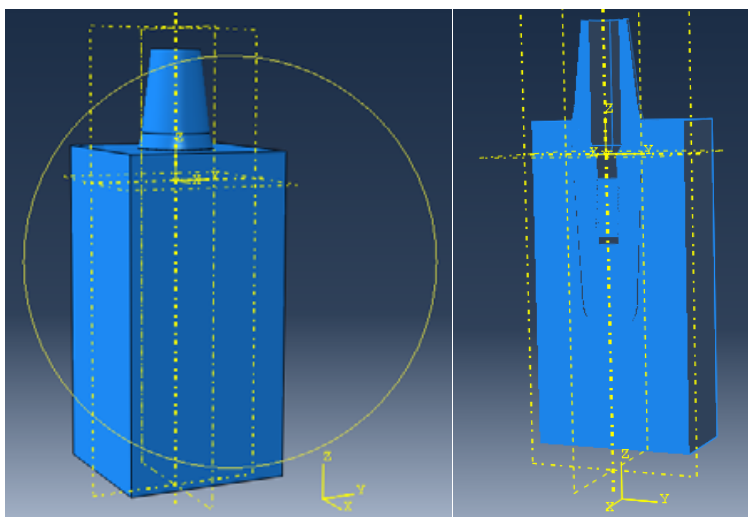

3-2)
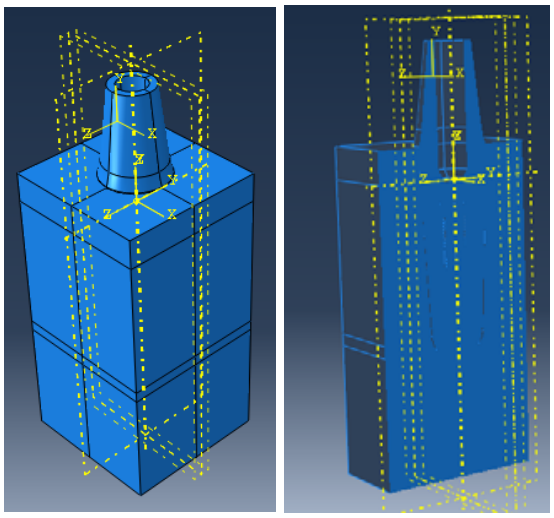

Figure3. Assmbled model of the system of sample A and B - 3-1) Sample A. 3-2) Sample B 


\section{Results}

The maximum stress value in the peri-implant bone, one- and two-piece abutment, abutment screw and the implant were evaluated and compared (Table 3).

Table 3. Maximum von Mises stress values in Sample A and B in the finite element model

\begin{tabular}{ccccc}
\hline Sample & $\begin{array}{c}\text { Maximum } \\
\text { von Mises } \\
\text { stress in bone }\end{array}$ & $\begin{array}{c}\text { Maximum von } \\
\text { Mises stress in } \\
\text { implant }\end{array}$ & $\begin{array}{c}\text { Maximum von } \\
\text { Mises stress in } \\
\text { abutment }\end{array}$ & $\begin{array}{c}\text { Maximum von } \\
\text { Mises stress in } \\
\text { abutment screw }\end{array}$ \\
\hline $\begin{array}{c}\text { A.System with Two-piece } \\
\text { abutment }\end{array}$ & 82 & 106 & 142 & 424 \\
$\begin{array}{c}\text { B.System with One-piece } \\
\text { abutment }\end{array}$ & 119 & 129 & 91 & - \\
\hline
\end{tabular}

3.1 Stress analysis for the system with two-piece abutment

Maximum stress concentration in the two-piece abutment was $142 \mathrm{Mpa}$ in the upper part of the connection hex of the abutment.

Maximum stress concentration in the screw of two-piece abutment was $424 \mathrm{Mpa}$ in the lower part of the screw in the last thread.

3.2 Stress analysis for the system with one-piece abutment

Maximum stress concentration in the one-piece abutment was $91 \mathrm{Mpa}$ in the upper part of abutment body.
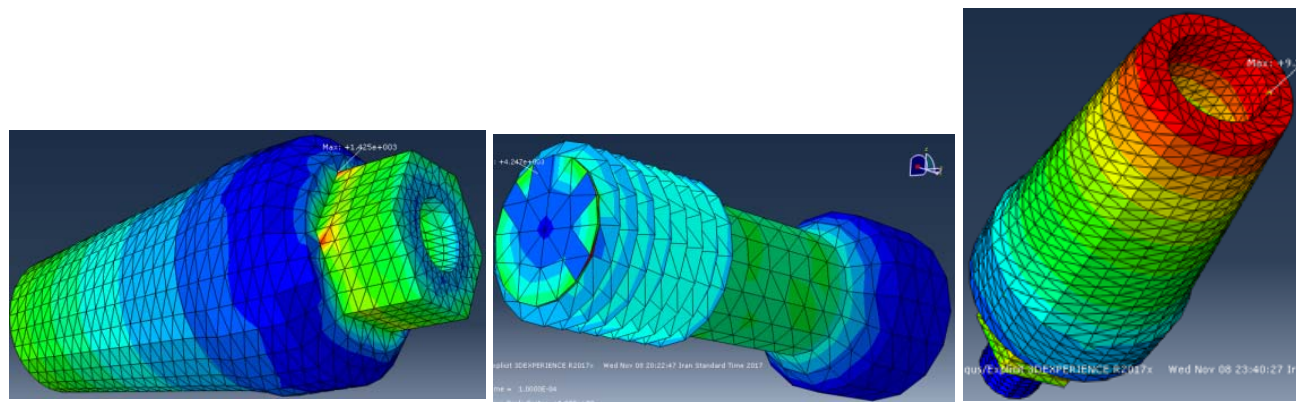

Figure4. Stress distribution of the components of the one- and two-piece abutment

\section{Discussion}

The present study was designed in an effort to compare the stress patern which will be produced by using one and two-piece abutments in screw-retained restorations using a 3-dimensional finite element analysis. The simulated bite force used in this study was $250 \mathrm{~N}$ vertical force with $4 \mathrm{~Hz}$ frequency which was applied to the center of the upper surfaces of the abutmnets.

The study demonstrated that the stress concentration in the peri-implant bone in the model with one-piece abutment was greater than that of the two-piece one. The results of a photoelastic study by Ochiaiet al17 showed that non-segmented abutments which are subjected to vertical loading create more non-lateral stress concentration in the bone as compared to the segmented abutments. According to Rangert et al the flexibility of the implant components can give some freedom of movement, and therefore reduce stress. This finding is consistent with the results of our study, which showed reduced microstrain in peri-implant bone with the twopiece abutment. The results of the present study demonstrated that stress values for models with one-piece abutment were in the pathologic overload zone, whereas these values for the two-piece abutment were within ideal loading zone. From a biological aspect, it can be concluded that using two-piece abutments for screwretained restorations is more suitable in reducing bone stress and strain.

The stress produced in the the screw of two piece abutment under dynamic loading (497 MPa) was much greater than the stress value in the one-piece abutment $(133 \mathrm{MPa})$. As there is a high stress concentration in the twopiece abutment screw compared to the one-piece one, it seems necessary to control the over-loading conditions to avoid clinical complications such as screw loosening and/or fracture. Since the abutment screw is the weakest component of the assembly, loosening of this screw can be a good indicator of the overloading condition and to identify an overloading problem before progress to a more serious situation such as fracture of the implant (especially with internal connections)and resorption of bone. Furthermore, stress concentration at bone-implant interface was less than that in the abutment screw. 
According to the results of this study, two-piece abutments are a better clinical choice than one-piece ones considering less stress concentration developed in bone. One of the limitations of FEA studies is considering all materials as homogeneous and isotropic with linear elasticity; this may limit extending the results to clinical situations. In addition, all FEA studies assume $100 \%$ osseointegration at bone-implant interface, which is not the case in biologic or clinical situations.

The majority of previous FEA studies have not modeled real components of the implant systems. In our modeling, resemblance to real models was achieved as much as possible. Therefore, the results of this study may allow a more logical selection of appropriate abutments of dental implants. In addition, our results may be useful in designing new abutments in dental implant systems with reduced biomechanical risk factors, leading to lower rates of failure.

Distribution and magnitude of stresses within an implant are influenced by the implant dimensions and geometry as documented by some authors. Catastrophic mechanical failure of an implant may occur by implant fatigue, implant fractures, veneering resin/ceramic fractures or other mechanical retention failures. Therefore, from both engineering and clinical perspectives, an important criterion in designing an implant system is to include a geometry that can minimize mechanical failures caused by an extensive range of loading.

The internal connection between different parts of the implant systems has a significant role in transferring masticatory load from the occlusal plane to the fixture and surrounding bone. Understanding the biomechanical aspects of different types of connections, (in particular the abutment implant connection), and their effects on stress/strain fields in implant/bone systems may assist in reducing the risk of implant failure.

Successful modeling depends on accurate stimulation of geometry and surface structure of the implant, material characteristics of the implant and jawbone, loading support conditions, and the biomechanical implant-jawbone interface. In this study, scanned images of the components of actual commercially available implant systems were used.

\section{Conclusion}

According to the results of this study, two-piece abutments are better clinical choices than one-piece ones considering less stress concentration developed in bone. The stress concentration whivh occurs in the screw of two-piece abutment leads to screw-loosening which helps the clinician to recognize over-loading situation and lets them prevent catastrophic mechanical failure of the implant and fracture of the peri-implant bone.

\section{Acknowledgments}

This study was supported by Islamic Azad University, Science and research branch. The author thanks the Iranian company for supplying the fixtures used in this research: Xarrin Advanced Technologies Co. which is distributors of BioHorizons Co. in Iran.

\section{References}

[1] Anitua E, Orive G. Finite element analysis of the influence of the offset placement of an implant-supported prosthesis on bone stress distribution. J Biomed Mater Res B Appl Biomater 2009;89:275-81.doi: 10.1002/jbm.b.31213.

[2] Ali Balik, DDS , Effects of Different Abutment Connection Designs on the Stress Distribution Around Five Different Implants: A 3Dimensional Finite Element Analysis , 2012

[3] Bozkaya D, Muftu S, Muftu A. Evaluation of load transfer characteristics of five different implants in compact bone at different load levels by finite elements analysis. J Prosthet Dent 2004; 92:523-30.doi: 10.1016/j.prosdent.2004.07.024.

[4] Carlson B, Jonsson G, Sandahl L. A 1-year clinical report of a one-piece implant abutment. Int J Prosthodont 2001;14:159-63.

[5] Five different implants in compact bone at different load levels by finite elements analysis, Journal of Prosthetic Dentistry, 92, 523$530,2004$.

[6] Goodacre CJ, Bernal G, Rungcharassaeng K. Clinical com-plications with implants and implant prostheses. J Prosthet Dent 2003;90:121-32.

[7] G. Tepper, R. Haas, W. Zechner, W. Krach, G. Watzek, Three-dimensional finite element analysis of implant stability in the atrophic posterior maxilla, Clinical Oral Albrektsson T, Branemark PI, Hansson HA, Lindstrom J. Osseointegrated titanium implants: requirements for ensuring a long-lasting, direct bone-to-implant anchorage in man. Acta Orthop Scand. 1981;52:155-170.

[8] Geng JP, Tan KBC, Liu GR. Application of finite element analysis in implant dentistry: a review of the literature. J Prosthet Dent. 2001;85:585-598.

[9] Glantz PO, Rangert B, Svensson A, et al. On clinical loading of osteointegrated implants: a methodological and clinical study. Clin Oral Implants Res. 1993;4:99-105.

[10] Hoshaw SJ, Brunski JB, Cochran GVB. Mechanical loading of Branemark implants affects interfacial bone modelling and remodeling. Int J Oral Maxillofac Implants. 1994;9:345-360.

[11] Heckmann SM, Karl M, Wichmann MG, Winter W, Graef F, Taylor TD. Cement fixation and screw retention: parame-ters of passive fit. An in vitro study of three-unit implant-supported fixed partial dentures. Clin Oral Implants Res2004;15:466-73.doi: $10.1111 / \mathrm{j} .1600-0501.2004 .01027 . x$.

[12] J. Mackerle, Finite element analyses and simulations in biomedicine: A bibliography. Engineering Computations. 17, 813-856, 2000.

[13] Manoj Shetty , Krishna Prasad D. , Naresh H. G. Shetty \&Raghavendra Jaiman , Implant Abutment Connection: Biomechanical Perspectives , 2014

[14] M.H. Ho, S.Y Lee, H.H. Chen, M.C. Lee, Three-dimensional finite element analysis of the effects of posts on stress distribution in dentin, Journal of Prosthetic Dentistry.; 72, 367-372, 1994.

[15] Montero J, Manzano G, Beltrán D, Lynch CD, Suárez-García MJ, Castillo-Oyagüe R. Clinical evaluation of the incidence of prosthetic complications in implant crowns constructed with UCLA castable abutments: A cohort fol-low-up study. J Dent2012;40:1081-9.doi: 10.1016/j.jdent.2012.09.001. 
[16] Mericske-Stern R, Zarb GA. In vivo measurements of some functional aspects with mandibular fixed prostheses supported by implants. Clin Oral Implants Res. 1996;7:153-161.

[17] Nergiz I, Schmage P, Shahin R. Removal of a fractured im-plant abutment screw: A clinical report. J Prosthet Dent 2004;91:513-17.

[18] N. Verdonschot, W.M. Fennis, R.H. Kuijs, J. Stolk, C.M. Kreulen, N.H. Creuqers, Generation of 3-D finite element models of restored human teeth using micro-ct techniques, International Journal Prosthodontics. 14, 310-315, 2001. D. Bozkaya, S. Muftu and A. Muftu, Evaluation of load transfer characteristics of

[19] O.L. Koca, G. Eskitascioglu and A. Usumez, Three-dimensional finite-element analysis of functional stresses in different bone locations produced by implants placed in the maxillary posterior region of the sinus floor, Journal of Prosthetic Dentistry. 93, 38-44, 2005.

[20] Rangert B, Gunne J, Glantz PO, Svensson A. Vertical load distribution on a three-unit prosthesis supported by a natural tooth and a single Brånemark implant. An in vivo study. Clin Oral Implants Res 1995;6:40-6.

[21] Simon Martinez, A variable finite element model of the human masticatory system for different loading conditions , 2013

[22] Siadat H, Hashemzadeh S, Geramy A, Bassir SH, Alikhasi M. The Effect of Offset Implant Placement on the Stress Distribution around a Dental Implant: a three-dimensional Finite Element Analysis. J Oral Implantol 2015;41:646-51.doi: 10.1563/AAID-JOI-D13-00163.

[23] Sakhavat Mammadzada, Celal Artunç, Faruk Sen, Mehmet Ali Güngör, Effect of abutment and implant shapes on stresses in dental applications using FEM, 2011

[24] Simon RL. Single implant-supported molar and premolar crowns: A ten-year retrospective clinical report. J Prosthet Dent 2003;90:517-21.

[25] Schwartz MS. Mechanical complications of dental implants. Clin Oral Implants Res.

[26] Yoshiyuki Hagiwara, Does platform switching really prevent crestal bone loss around implants? , 9 November 2009 